\title{
Review and Analysis of Key Techniques in Marine Sediment Sampling
}

\author{
Shudong He, Youduo Peng* ${ }^{*}$, Yongping Jin, Buyan Wan and Guangping Liu
}

\begin{abstract}
Deep-sea sediment is extremely important in marine scientific research, such as that concerning marine geology and microbial communities. The research findings are closely related to the in-situ information of the sediment. One prerequisite for investigations of deep-sea sediment is providing sampling techniques capable of preventing distortion during recovery. As the fruit of such sampling techniques, samplers designed for obtaining sediment have become indispensable equipment, owing to their low cost, light weight, compactness, easy operation, and high adaptability to sea conditions. This paper introduces the research and application of typical deep-sea sediment samplers. Then, a representative sampler recently developed in China is analyzed. On this basis, a review and analysis is conducted regarding the key techniques of various deep-sea sediment samplers, including sealing, pressure and temperature retaining, low-disturbance sampling, and no-pressure drop transfer. Then, the shortcomings in the key techniques for deep-sea sediment sampling are identified. Finally, prospects for the future development of key techniques for deep-sea sediment sampling are proposed, from the perspectives of structural diversification, functional integration, intelligent operation, and high-fidelity samples. This paper summarizes the existing samplers in the context of the key techniques mentioned above, and can provide reference for the optimized design of samplers and development of key sampling techniques.
\end{abstract}

Keywords: Sampler, Sealing technique, Pressure \& temperature-retaining technique, Low-disturbance sampling technique, No-pressure drop transfer technique

\section{Introduction}

Deep-sea sediment is of great importance for understanding changes in the Earth's environment, predicting future environmental and climate changes, exploiting and utilizing new energy sources on the seabed, and studying the extreme microbial diversity of oceans and biological genetic resources [1]. However, due to the existence of water layers, the knowledge and utilization of marine resources are greatly restricted [2]. To overcome this restriction, deep-sea sediment samplers have emerged. Since the first sampling of deep-sea sediment by humans in 1872, deep-sea sediment samplers have become indispensable technical equipment for seabed resource

\footnotetext{
*Correspondence: ydpeng1964@163.com
}

National-Local Joint Engineering Laboratory of Marine Resources Exploration Equipment and Safety Technology, Hunan University of Science and Technology, Xiangtan 411201, China exploration, marine geological surveys, and marine scientific investigations [3-5], and have been valued and applied by the world's maritime powers. Many scientific research findings have been applied to actual marine survey projects, and considerable economic and social benefits have been achieved, highlighting the scientific value of deep-sea sediment samplers [6, 7].

However, as people pay more attention to the ocean and sampling requirements, deep-sea sampling also faces many problems. For example, interactions between the sampler and sediment cause the original layer of the sediment to bend, deform, and compress, thereby destroying the integrity of the sample information [8]. Sampling in a high-pressure, low-temperature water environment will also cause changes in the pressure and temperature of the sample, leading to gas phase dissolution, component loss, decomposition of organic matter, death of barophilic microorganisms, changes of chemical gradients, 
changes of oxidation states of variable ions, etc. $[9,10]$. Therefore, identifying how to provide the most primitive sediment samples for human activities and scientific research has remained the focus of research worldwide.

The parts of this paper are organized as follows. Section 2 addresses typical samplers used worldwide. Section 3 summarizes existing samplers in the context of the key techniques of sealing, pressure and temperatureretaining, and reducing or eliminating disturbances and pressure drop transfers, providing reference for the optimized design of samplers and development of key sampling techniques. In Section 4, the shortcomings of the key techniques for deep-sea sediment sampling are identified, and future development prospects are proposed.

\section{Application of Deep-Sea Sediment Sampler}

Currently, deep-sea sediment samplers mainly include the following devices: the pressure core barrel (PCB) [11] (Figure 1) adopted by the Deep Sea Drilling Project, advanced piston corer (APC) [12] and pressure core sampler (PCS) [13] (Figure 2) adopted by the Ocean Drilling Program, Fugro pressure corer (FPC) (Figure 3) and rotary corer (HRC) (Figure 4) used in hydrate auto-clave coring equipment (HYACE) $[14,15]$, pressure temperature core sampler (PTCS) [16] and hybrid PCS [17] (Figure 5) developed by the Japan Agency for Marine-Earth Science and Technology, multiple autoclave corer (MAC) and dynamic autoclave piston corer(DAPC) designed by the German Ministry of Education and Research [18], high pressure temperature coring system (HPTC) developed by the Gulf of Mexico Joint Industry Project [19], and MeBo Druckkern Probennehmer (MDP) [20] developed by the MeBo German Ministry of Education and Research. Detailed descriptions of the samplers mentioned above have been provided in many documents, and thus will not be repeated here [21] (Table1).

The research on deep-sea sediment samplers in China started relatively late (in the 1980s), and the related research also lagged behind developed countries, such as the United States, Japan, and Germany. In recent years, with the increasing tension regarding global energy and great importance attached to the exploitation of marine resources, China has also intensified its research on deep-sea sediment exploration [22]. In 2007, China officially launched a national high-tech $R \& D$ program (863 Program) for managing research in the marine technology field. Two key projects were included in the program: one concerned a technique for designing pressure-and temperature-retaining samplers and treating the collected samples, and the other was a natural gas hydrate coring technique [23, 24]. In 2016, China officially launched research on key projects of the national R\&D program, including "Deep-Sea Key Technologies and Equipment" [25-27].

\subsection{Non-pressure Insulation Corer}

In 2016, Lu et al. from the National Deep Sea Center proposed a motor-driven sampler comprising cobalt-rich crust core samplers mounted on a"Jiao Long" manned submersible $[28,29]$. The sampler was mainly comprised of a battery, control system cabin, start-stop trigger magnet, deep-sea motor and flexible transmission shaft, gearbox, core drilling tool, and clamp handle. After the sampler reached a designated position in a cobalt-rich crust mine area, the submarine operator manipulated the mechanical arms to position the sampler and drill for samples. The power source of the sampler was the deep-sea battery, as combined with the deep-sea motor. The power of the battery was $400 \mathrm{~W}$. The maximum working water depth was $4000 \mathrm{~m}$, and the collected seabed cobalt-rich crust samples reached up to $100 \mathrm{~mm}$ in length and $16 \mathrm{~mm}$ in diameter. The rock stratum hardness value was greater than or equal to six. After the drilling test, the sampler was mounted on the "Jiao Long" manned submersible; two submersible sampling operations were conducted during the 37th China Ocean voyage. The drilling lasted approximately 20 min each time and several rock core samples were obtained, meeting the requirements for deep-sea applications. The sampler was designed to collect cobalt-crusted hard rock samples, and thus did not apply any techniques for pressure and temperature-retention.

In 2003, a research team at Hunan University of Science and Technology led by Professor Wan Buyan developed China's first deep-sea shallow seabed sampling drilling rig [30-32]. The sampling rig was powered by an underwater battery or umbilical cable, with a drilling depth of $0.7-2 \mathrm{~m}$. The rig conducted core sampling over 1000 times within $3000 \mathrm{~m}$ in the Pacific and Indian Oceans during the China Ocean resource survey voyages. It has conducted the most core samplings in real seabed environments world wide. In 2005, the seabed sampling rig was operated in the sea 147 times and 111 core samples were obtained, ultimately contributing to United Nations approval of exploitation rights for an international seabed mining area. In 2008, a cobalt-rich crust drill with a unique multiple coring function was successfully developed by the 863 Program, and has been successfully applied in investigations conducted during the China Ocean voyages [33].

In 2015, the Hunan University of Science and Technology and Guangzhou Marine Geological Survey jointly developed the "Hainiu" sampling rig [34]. This sampling rig was suitable for a water depth of $3500 \mathrm{~m}$ and drilling depth of $90 \mathrm{~m}$. It could obtain a core with a diameter of $62 \mathrm{~mm}$. It was equipped with one drilling tool of $3.3 \mathrm{~m}, 23$ drill pipes of $2.5 \mathrm{~m}$, and 24 core pipes of $3 \mathrm{~m}$. It adopted rope coring for coring soft mud 
Table 1 Key techniques for sampling deep sea sediments

\begin{tabular}{|c|c|c|c|c|c|c|c|c|}
\hline \multirow[t]{2}{*}{ Samplers } & \multicolumn{3}{|c|}{ Performances parameters } & \multirow{2}{*}{$\begin{array}{l}\text { Sealing } \\
\text { techniques }\end{array}$} & \multirow{2}{*}{$\begin{array}{l}\text { Pressure- } \\
\text { retaining } \\
\text { techniques }\end{array}$} & \multirow{2}{*}{$\begin{array}{l}\text { Temperature- } \\
\text { retaining } \\
\text { techniques }\end{array}$} & \multirow{2}{*}{$\begin{array}{l}\text { Low } \\
\text { disturbance } \\
\text { techniques }\end{array}$} & \multirow{2}{*}{$\begin{array}{l}\text { No pressure- } \\
\text { drop transfer } \\
\text { technique (Yes/ } \\
\text { No) }\end{array}$} \\
\hline & $\begin{array}{l}\text { Core length } \\
\text { (m) }\end{array}$ & $\begin{array}{l}\text { Core } \\
\text { diameter } \\
(\mathrm{mm})\end{array}$ & $\begin{array}{l}\text { working } \\
\text { pressure } \\
(\mathrm{MPa})\end{array}$ & & & & & \\
\hline DSDP-PCB & 6 & 57.8 & 35 & $\begin{array}{l}\text { Steel-on-steel } \\
\text { and valve }\end{array}$ & PRT & N/A & DLTS,STST & No \\
\hline ODP-PCS & 1 & 42 & 70 & $\begin{array}{c}\text { Steel-on-steel } \\
\text { and valve }\end{array}$ & PRT & N/A & $\begin{array}{l}\text { DLTS, Gap } \\
\text { between the } \\
\text { DLTS }\end{array}$ & Yes \\
\hline FPC & 1 & 58 & 25 & Piston and flap & PRT & PTRT & $\begin{array}{l}\text { DLTS, Piston } \\
\text { structure }\end{array}$ & No \\
\hline HRC & 1 & 50 & 25 & Piston and flap & PRT & PTRT & $\begin{array}{l}\text { DLTS, Piston } \\
\text { structure }\end{array}$ & No \\
\hline PTCS & 3 & 66 & 30 & $\begin{array}{l}\text { Steel-on-steel } \\
\text { and valve }\end{array}$ & PRT & ATRT & DLTS, STST & No \\
\hline Hybrid PCS & 3.5 & 51 & 35 & $\begin{array}{l}\text { Steel-on-steel } \\
\text { and valve }\end{array}$ & PRT & PTRT & DLTS, STST & No \\
\hline MAC & 0.55 & 100 & 14 & Piston and flap & PPRT & PTRT & $\begin{array}{l}\text { Piston structure, } \\
\text { Special cutter, } \\
\text { Core catcher }\end{array}$ & No \\
\hline DAPC & 2.5 & 84 & 20 & $\begin{array}{l}\text { Piston and ball } \\
\text { valve }\end{array}$ & PPRT & PTRT & $\begin{array}{c}\text { Piston structure, } \\
\text { Special cutter, } \\
\text { Core catcher }\end{array}$ & No \\
\hline HPTC & 3.5 & 54 & 35 & $\begin{array}{l}\text { Double ball } \\
\text { valve }\end{array}$ & PRT & PTRT & $\begin{array}{l}\text { Special cutter, } \\
\text { Rotary sam- } \\
\text { pling, Core } \\
\text { catcher }\end{array}$ & No \\
\hline MDP & 1.3 & 45 & 20 & $\begin{array}{l}\text { Steel-on-steel } \\
\text { and flap }\end{array}$ & PRT & N/A & $\begin{array}{l}\text { Special cutter, } \\
\text { Core catcher }\end{array}$ & No \\
\hline TRC & 0.5 & 48.5 & 60 & $\begin{array}{l}\text { Double ball } \\
\text { valve }\end{array}$ & PPRT & N/A & $\begin{array}{l}\text { DLTS, Diamond } \\
\text { drilling tool }\end{array}$ & No \\
\hline $\mathrm{PIC}$ & 12 & 65 & 30 & Piston and flap & PPRT & N/A & Special cutter & No \\
\hline MHPIC & 0.29 & 69 & 70 & $\begin{array}{l}\text { Steel-on-steel } \\
\text { and flap }\end{array}$ & PPRT & PTRT & Special cutter & No \\
\hline HPTP & 11.2 & 104 & 30 & $\begin{array}{l}\text { Steel-on-steel } \\
\text { and flap }\end{array}$ & PPRT & PTRT & DLTS, BHA & No \\
\hline PRMSC & 0.073 & 300 & 60 & $\begin{array}{l}\text { Double ball } \\
\text { valve }\end{array}$ & APRT & PTRT & $\begin{array}{c}\text { Piston structure, } \\
\text { Special cutter }\end{array}$ & No \\
\hline HBFC & 0.052 & 100 & 30 & $\begin{array}{l}\text { Double ball } \\
\text { valve }\end{array}$ & PRT & PTRT & DLTS, BHA & No \\
\hline IVBP & N/A & N/A & N/A & Ice seal & PRT & ATRT & DLTS, BHA & No \\
\hline
\end{tabular}

PPRT: Passive pressure-retaining technique with external accumulator; APRT: Active pressure-retaining technique with external accumulator; PRT: Pressure-retaining technique with internal accumulator; PTRT: Passive temperature-retaining techniques; ATRT: Active temperature-retaining techniques; DLTS: Double layered tube structure; STST: Smooth thin-wall sampling tube; DSDP-PCB: Deep Sea Drilling Project-advanced piston corer; ODP-PCS: Ocean Drilling Program-PCS; FPC: Fugro pressure corer; HRC: hydrate auto-clave coring equipment rotary corer, PTCS: pressure temperature coring system; MAC: multiple autoclave corer; DAPC: dynamic autoclave piston corer; HPTC: high pressure temperature coring system; MDP: MeBo Druckkern Probennehmer; TRC: tight rock corer; PIC: pressure and insulation corer; MHPIC: manipulator holding PIC; HPTP: hydraulic pressure and temperature preservation corer; PRMSC: pressure-retained multi-tube sediment corer; HBFC: hole bottom freezing corer for gas hydrates; IVBP: wire line ice-valve-based pressure corer

and hard rock. In addition, it was equipped with a multi-functional in-situ test instrument for performing in-situ tests on the end resistance, friction force, pore water pressure, and temperature of the layers, and for taking pictures of soil particles. It has become representative of China's seabed drilling rigs. The "Hainiu" deep-sea drilling rig successfully completed a sea trial in the South China Sea in June 2015. In August 2018, it collected the first natural gas hydrate core samples in the South China Sea. The length of the total samples was $346.48 \mathrm{~m}$, and the average core-taking rate reached as high as $90.98 \%$. Thus, a new breakthrough in China's equipment for marine mineral resources exploration and acquisition was achieved. 


\subsection{Pressure Corer}

In 2009, the Changsha Institute of Mining Research designed a tight rock corer (TRC) [35] (Figure 6) capable of obtaining hard cores. The sampler included an outer tube, sampling tube, pressure-compensation cylinder, transmission, motor, high-pressure ball valve components, and pumps. The outer tube of the sampler was connected to transmission equipment. Driven by the motor, the core sampling head rotated with the outer tube, and a cylindrical core was obtained during the continuous drilling process. When the sampling was completed, the water pump began operation; the driving water flowed through the space between the outer tube and sampling tube to the bottom of the sampling tube, and the cylindrical core moved upward into the pressurecompensation cylinder under hydrodynamic action. At this time, two high-pressure ball valves located above and below the pressure-compensation cylinder were closed, and then the pressure-compensation cylinder was sealed. A pressure-compensating cylinder released pressure to compensate for the loss of pressure within the pressure-compensation cylinder. The sampler was designed for hard cores, which can maintain the pressure of the sample. The sampler had good pressure-retaining performance, but did not have any techniques for retaining temperature.

In 2016, Zhejiang University, Shanghai Jiao Tong University, and Hunan University of Science and Technology jointly undertook a National Key R\&D Program of China entitled "Development of the Gas-tight Sampler for Fullocean-depth Sediment." Among them, the Marine Engineering Laboratory of Hunan University of Science and Technology developed a gas-tight sampler for full-oceandepth sediment. The maximum working water depth of the sampler can reach $11500 \mathrm{~m}$; the sample diameter is $54 \mathrm{~mm}$, and the coring depth is more than $350 \mathrm{~mm}$. The sampler is simple in structure, and easy to operate. The sampler can be mounted on a remotely operated vehicle (ROV), and only a single mechanical arm is needed to collect the sediment and seal it. During the recovery of the sampler, a pressure-compensation device can be used for real-time pressure compensation of the sample, to realize pressure-retaining sampling. The sediment sampler is an important supporting facility for scientific research on manned submersibles in China. However, the temperature-retaining function of the sampler has not been applied, and a sea trial has yet to be completed.

\subsection{Pressure and Insulation Corer}

Qin et al. from Zhejiang University proposed a manipulator-holding pressure and insulation corer (MHPIC) [36] (Figure 7). The sampler was mainly composed of sampling parts, pressure-resistant parts, pressure-holding parts, pressure-compensation parts, and an auxiliary frame structure. The sampling parts comprised a knife barrel, sampling tube, and handle; the pressure-holding parts comprised a pressure-holding cylinder body and upper and lower end covers. When sampling, the sampling tube was located outside the pressure-holding cylinder, and a flap was opened and placed on the side of the pressure-holding cylinder. When the sampler reached the designated location, the manipulator was forced to press down, and the sampler was inserted into the sediment vertically. When the sediment entered the sampling tube, another manipulator pulled the handle upwards, and the sampling tube entered the pressure-holding cylinder. Then, the flap was closed to seal the sample and hold the pressure. The sampler had a design pressure of $70 \mathrm{MPa}$ and a working water depth of $7000 \mathrm{~m}$. It could collect samples of seabed sediment up to $290 \mathrm{~mm}$ in length and $69 \mathrm{~mm}$ in diameter.

The hand-held sediment pressure-holding sampler pulled the sampling tube into the pressure-holding cylinder using manned submersible manipulators. It did not require a submersible to provide power, or another power source. It was light and portable, allowing the manipulators to change the samplers for unlimited sampling in time and place. It had a pressure-compensator for maintaining the pressure of samples. The pressure changes of the samples did not exceed 15\% within $6 \mathrm{~h}$, and the pressure holding effect was good. Passive insulation was achieved through an insulation material and plating technique.

In 2006, the State Key Laboratory of Oil and Gas Reservoir Geology and Exploitation(of Southwest Petroleum University) developed a hydraulic pressure and temperature preservation corer (HPTP) [37]. The sampler mainly included a pressure chamber and sampling tube, hydraulic source, balance system, release mechanism, pressure compensator, drive mechanism, and sealing device. The pressure chamber was composed of four parts: an upper tube, middle tube, and lower tube, and retaining rings between each of the tubes. The sampler had a maximum working pressure of $30 \mathrm{MPa}$, and an operating temperature of 0 to $40{ }^{\circ} \mathrm{C}$. When the sampler reached the sampling point, the hydraulic source began operation, and the drive mechanism pushed the sampling drill into the seabed. When the sampling was completed, a solenoid valve sent a signal. At this time, the sampling tube was pulled up into the pressure chamber. Then, the flap located at the lower end of the pressure chamber was closed, and the sealing was completed. Thereafter, the pressure compensator released pressure to compensate for the loss of pressure in the pressure chamber. In addition, the sampler used a passive insulation method to maintain the temperature of the sample. Sampling tests 
at water depths of $1367 \mathrm{~m}$ and $1410 \mathrm{~m}$ in the northern part of the South China Sea obtained pressure-holding sediments of $850 \mathrm{~mm}$ and $1000 \mathrm{~mm}$, respectively. The pressure of the sediment rose by $6.5 \%-13.7 \%$ of the insitu pressure within $24 \mathrm{~h}$; the sediment temperature rose by $4.3-6.5^{\circ} \mathrm{C}$ within $170 \mathrm{~min}$. Thus, the sampler showed good pressure-and temperature-holding performance; it is currently mainly used for the collection of natural gas hydrates.

In 2014, Chen et al. of Zhejiang University proposed a novel subsea hydraulic pressure-retained multi-tube sediment corer (PRMSC) [38]. The sampler mainly consisted of a bracket, two independent sampling devices, a hydraulic system, and a real-time monitoring system. Each sampling device had a separate two-stage hydraulic system with a piston rod that connected toa sampling tube. Two ball valves were installed in the sampling tube, for sealing and holding the pressure of the pressure cylinder. Areal-time monitoring system included a camera with a light, along with an altimeter, attitude sensor, battery, and control unit, so that the sampler could be monitored in real time; the signal was transmitted to the deck via a coaxial cable. The ship operator could select an appropriate sampling position based on the monitoring signal, and could control the sampling speed and perform the sampling operation for the sediment. To validate its performance, an offshore test was conducted at a water depth of $1035 \mathrm{~m}$ in the South China Sea, and two sediment samples with in-situ pressures were successfully obtained. The sampler adopted the ball valve self-sealing technology, and the pressure-holding effect was good; the temperature of the sample was maintained by heating the sampling tube in a water bath.

In 2015, a schematic for a hole bottom freezing corer for gas hydrates (HBFC) [39] was developed by the Beijing Institute of Exploration Engineering of the China Geological Survey. It adopted a modular design, which mainly consisted of salvaging an anchor head, drive section, accumulator, valve block section, pressure-maintaining core cylinder, and pressure- maintaining valve section. The sampler was designed for a maximum working pressure of $30 \mathrm{MPa}$, and could collect a sample with a diameter of $52 \mathrm{~mm}$ and length of $1 \mathrm{~m}$. The sampler's temperature-maintaining mechanism used the structure of a vacuum tube (a double-layered tube which was vacuumed in the middle) to slow the heat exchange between the sampler and outside. The pressure-retaining function was achieved by a piston accumulator and flap sealing mechanism, which automatically compensated for the pressure of the sampling tube. A total of 18 samples were recovered from the South China Sea; 14 samples had pressures greater than $10 \mathrm{MPa}$, and the average pressuremaintaining ratio reached $77.7 \%$.

\section{Key Techniques for Sampling Deep-Sea Sediment}

\subsection{Sealing Technology}

One of the most evident features of modern samplers concerns maintaining the original pressure of the deepsea sediment. One prerequisite for holding pressure is the design of a reliable sealing structure for ensuring reliable sealing after the sample enters the pressure cylinder. At present, commonly used sampler sealing structures mainly include steel-on-steel seals (such as a steel-onsteel plus seal ring), piston seals, valve seals, flap seals, and ice seals. The seals used in deep-sea samplers are mostly combinations of the above-mentioned seals. The sealing structures of currently-used samplers can be classified into five types: steel-on-steel and valve, steel-onsteel and flap, piston and flap, double ball valve, and ice seal.

In the steel-on-steel and valve sealing technique, the upper end of the pressure-retaining cylinder or sampling tube is sealed by the steel-on-steel seal, and the lower end comprises a valve. There are mainly two types of valves: ball valves, and butterfly valves. The working principles of the two types of valves are basically the same. When sampling, the sampling tube is inserted into an annular hole of the rotary ball valve. After sampling, the sampling tube is lifted up, and the ball valve is rotated by $90^{\circ}$ under the action of the driving mechanism or external force, and the lower end of the pressure-retaining cylinder is sealed. Steel-on-steel seals are usually used in combination with O-shaped seal rings; this approach thus concerns a traditional way of sealing [40-42]. Ball valves have good wear resistance. They are ground manually, with reliable sealing performance and a long service life. This type of sealing is widely used in deep-sea samplers such as the PCB, PCS, and hybrid PCS.

In the steel-on-steel and flap sealing technique, the upper end of the pressure-retaining cylinder or sampling pipe is sealed by the steel-on-steel seal, and the lower end comprises a flap. When sampling, the flap opens under the action of the sampling pipe. After sampling, the sampling tube is lifted up to the exact point where it stopped contact with the flap, and the flap is turned over by a driving mechanism (such as a torsion spring). A cone surface is used to seal the lower end of the pressureretaining cylinder. Compared with the ball valve seal, the flap sealing structure is simpler; it avoids the problems of highly-precise cooperation, and is also easy to disassemble and maintain. Thus, the advantages are outstanding. The MHPIC uses this sealing technology.

In the sealing technique combining a piston and flap, the upper end of the pressure-retaining cylinder adopts a piston seal, and the lower end adopts a valve seal. This sealing structure is similar to the steel-on-steel-valve 
combined valve, except that the piston at the upper end of the sampling cylinder serves as a seal. After the sampling, the entire sampler is lifted by a wire rope connected to the piston (at which time the piston is in close contact with the sampling cylinder), and the top of the sampling cylinder is sealed. When the sampling cylinder enters the pressure chamber, the flap valve is closed by a driving mechanism, and the lower end of the pressure chamber is sealed. The use of a piston seal not only achieves a sealing effect, but also reduces the disturbance of the sediment during the sampling process. This type of sealing is widely used in deep-sea samplers. For example, the PTPC, MAC, DAPC, FPC, and HRC use this sealing structure. In addition, China's PIC (Figure 8) sampler uses this sealing method; the difference is that it uses a torsion spring to close the flap.

In the sealing technique based on a double ball valve, the upper and lower ends of the pressure-retaining cylinder and sampling pipe are sealed by ball valves. Compared with the combination of a steel-on-steel seal and valve, the double-ball valve seals are simple and compact in structure, good in sealing performance, and easy to operate and maintain. The upper and lower ends of the pressure cylinders of the HPTC, TRC, and TKP-1 are all sealed using rotary ball valves.

In the ice seal technique, an ice valve is used for sealing and holding pressure, i.e., the drilling fluid is frozen into an ice valve at the bottom of the core tube in situ, thereby forming a seal [43] (Figure 9). For sampling general sediment, most of the existing pressure-holding seals have used ball valves to seal the lower end of the core tube, which have worked well. However, in harsh environments rich in solid particles, a ball valve can have difficulty achieving a reliable seal, and sometimes cannot even be closed. Despite the design of a pressure compensator, it is difficult to completely compensate for the pressure drop in the core tube caused by the non-tight valve seal, resulting in low or no pressure. The ice seal structure is especially suitable for sampling in low-temperature environments of the deep sea, as there is no need to install moving parts (such as ball valves). Highly-precise cooperation and conventional seals are not needed. Practice has proven that the sampling technique of pressureretaining ice is highly adaptable to complex environments containing solid particles [44, 45].

At present, most of the pressure-retaining seals used in samplers are valve-based structures whose sealing performance is good. Except for the MHPIC, most samplers have adopted ball or butterfly valve seals, owing to the superior performance of these valves in the complex environments of the deep sea. However, the valve structure must overcome two difficulties: one is determining how to cooperate with an $\mathrm{O}$-shaped ring seal; the other is that the use of a valve seal will increase the complexity of the overall structure of the sampler, e.g., causing the need to use an external force or drive mechanism to rotate the ball valve to achieve the sealing effect. Therefore, there are now samplers (such as the MHPIC) that use flap seals to solve the above-mentioned difficulties. As the drive mechanism of flap seals is relatively simple, only a torsion spring is needed. At present, the ice seal structure is widely used in natural gas sampling [46-49].

\subsection{Pressure-Retaining Technique}

After the sampling, the sampling tube is transferred to the pressure cylinder, and the pressure cylinder is sealed when the first step of pressure retaining is completed. During the recovery process of the sampler, pressure losses may occur due to leakage, elastic deformation, and external temperature difference(s). Therefore, it is necessary to design a pressure-compensation device for the pressure cylinder. At present, the sampler

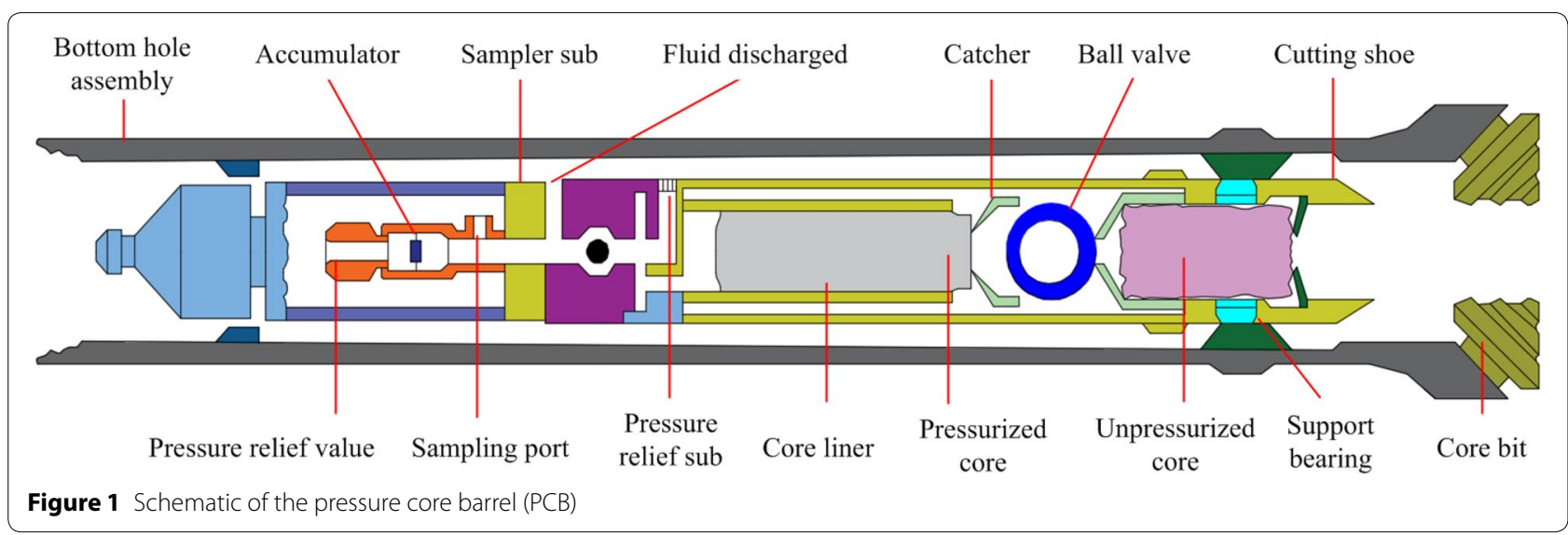




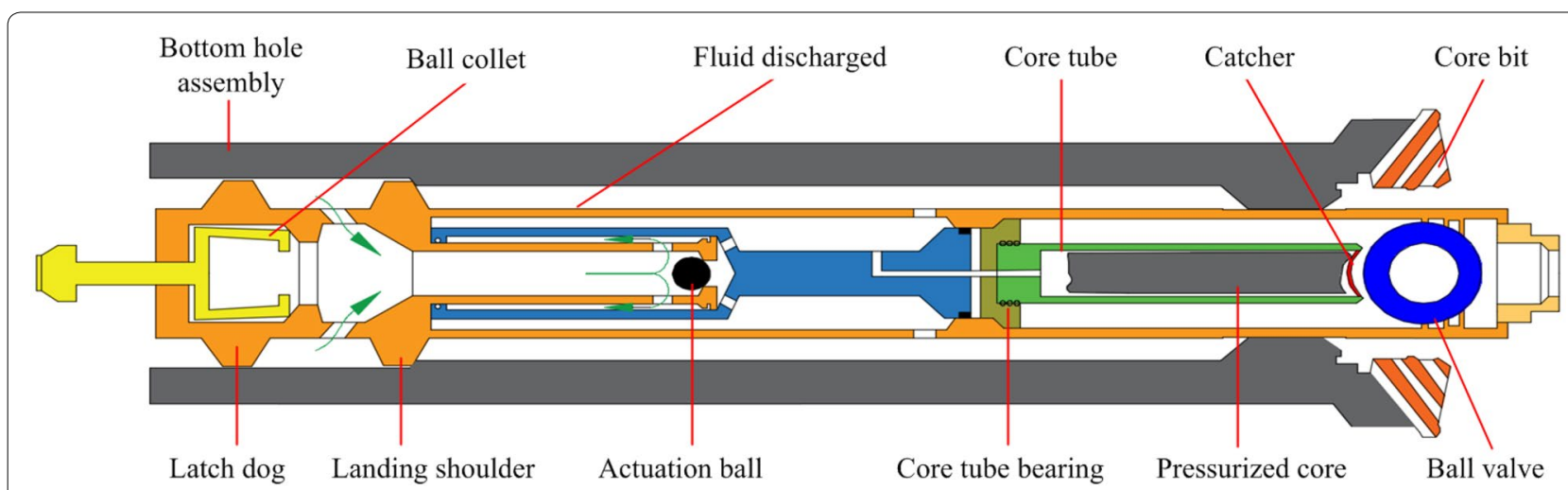

Figure 2 Schematic of the pressure core sampler (PCS)
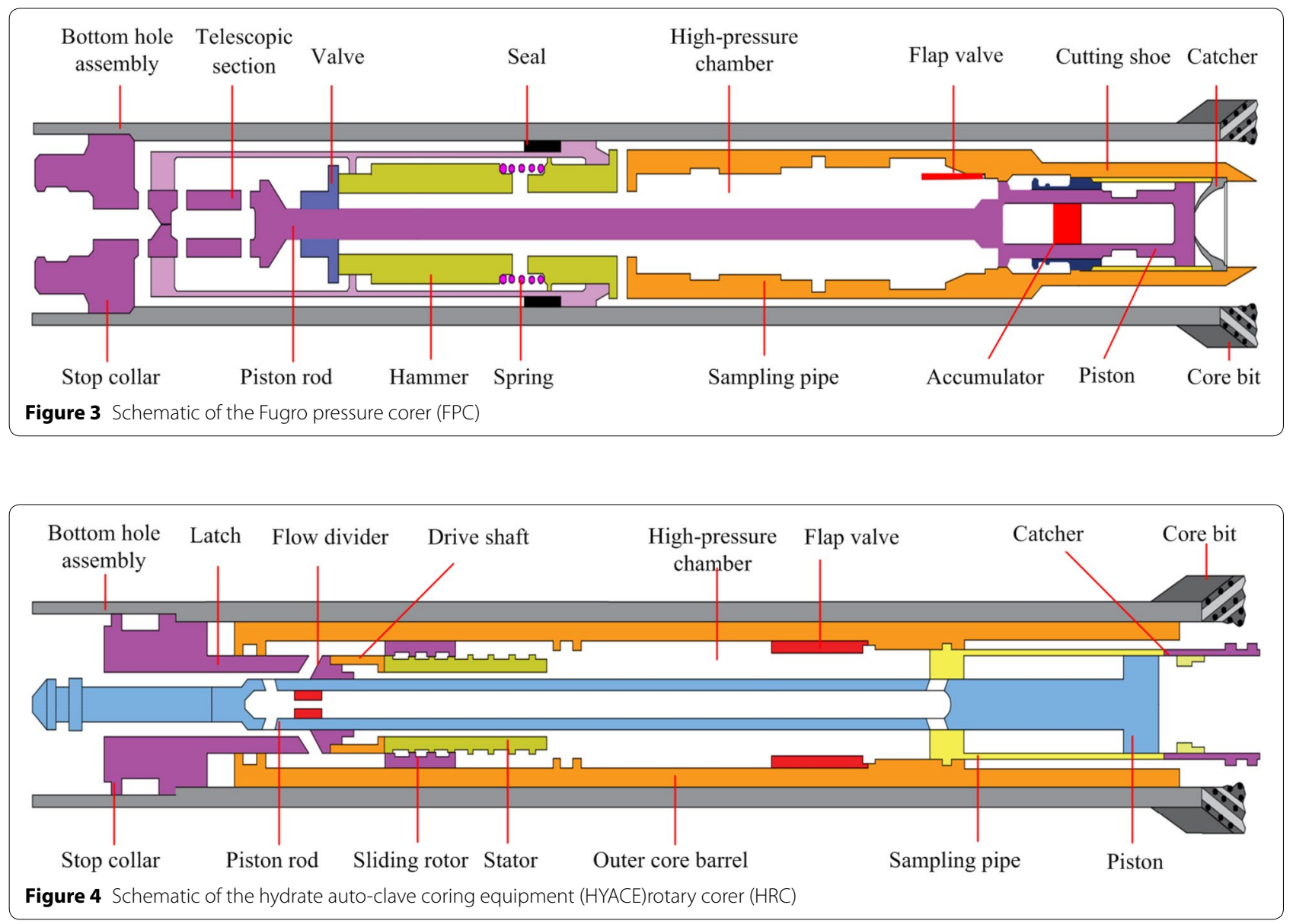

commonly uses accumulators to achieve pressure compensation. Such accumulators can be divided into three types: passive pressure-retaining techniqueswith an external accumulator (PPRTs), active pressure-retaining techniqueswith an external accumulator (APRTs), and pressure-retaining techniques with an internal accumulator.

\subsubsection{Passive Pressure-Retaining Technique with External Accumulator (PPRT)}

As shown in Figure 10, the entire accumulator is installed outside of the pressure cylinder, and the accumulator chamber is divided into upper and lower parts by the piston. The upper chamber is equipped with a pressure relief valve, and the upper chamber is pre-charged with 


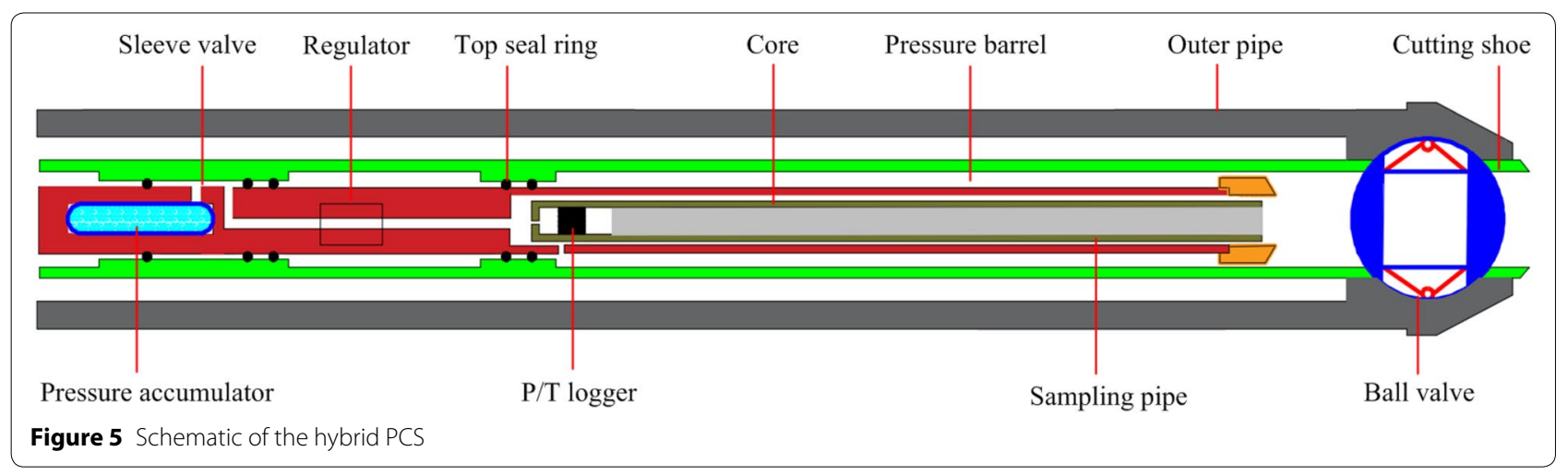

a certain pressure gas through a high-pressure hose and valve. The lower chamber is connected to the sampler pressure barrel through a high-pressure hose. The working principle is Boyle's law, i.e., the gas pressure is negatively and linearly related to the volume.

Before sampling, the accumulator is pre-charged with a certain pressure of gas (usually $70 \%-80 \%$ of the hydrostatic pressure at the sampling point) through the highpressure valve. During the diving of the sampler, as the pressure gradually increases, the piston in the accumulator moves up and the gas is compressed, resulting in increased pressure. When the working pressure of the upper chamber reaches the maximum level, the sleeve valve is opened to ensure a constant pressure in the pressure cylinder. After sampling, the accumulator releases the gas pressure, to compensate for the pressure loss in

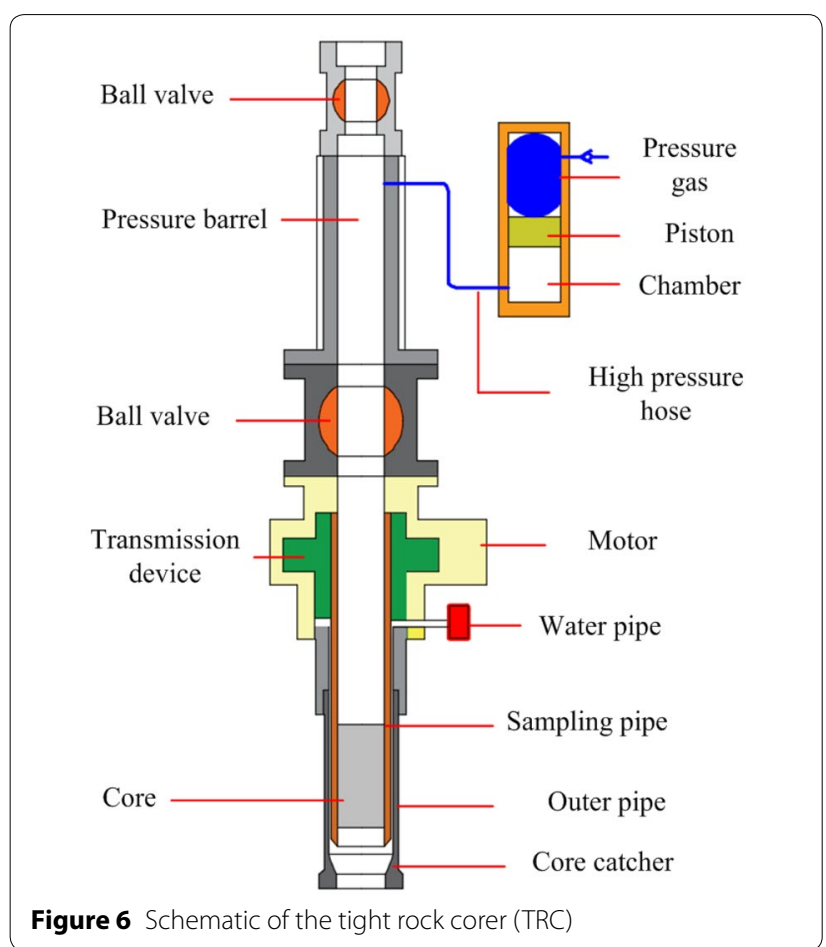

the pressure cylinder. The PPRT structure only requires a cylinder, piston, high-pressure valve and high-pressure hose. It is simple in structure, convenient to operate, and excellent in pressure-retaining performance. This pressure-retaining technique is widely used in deep-sea sampling; the MHPIC, HPTP, TRC, MAC, and DAPC all adopt this pressure-retaining technique.

\subsubsection{Active Pressure-Retaining Technique with External Accumulator (APRT)}

The APRT and the PPRT are similar in regards to working principle. The difference in the APRT concerns the pressure compensation control. As shown in Figure 11, the accumulator is equipped with a pressure sleeve valve and pneumathode. The pneumathode is

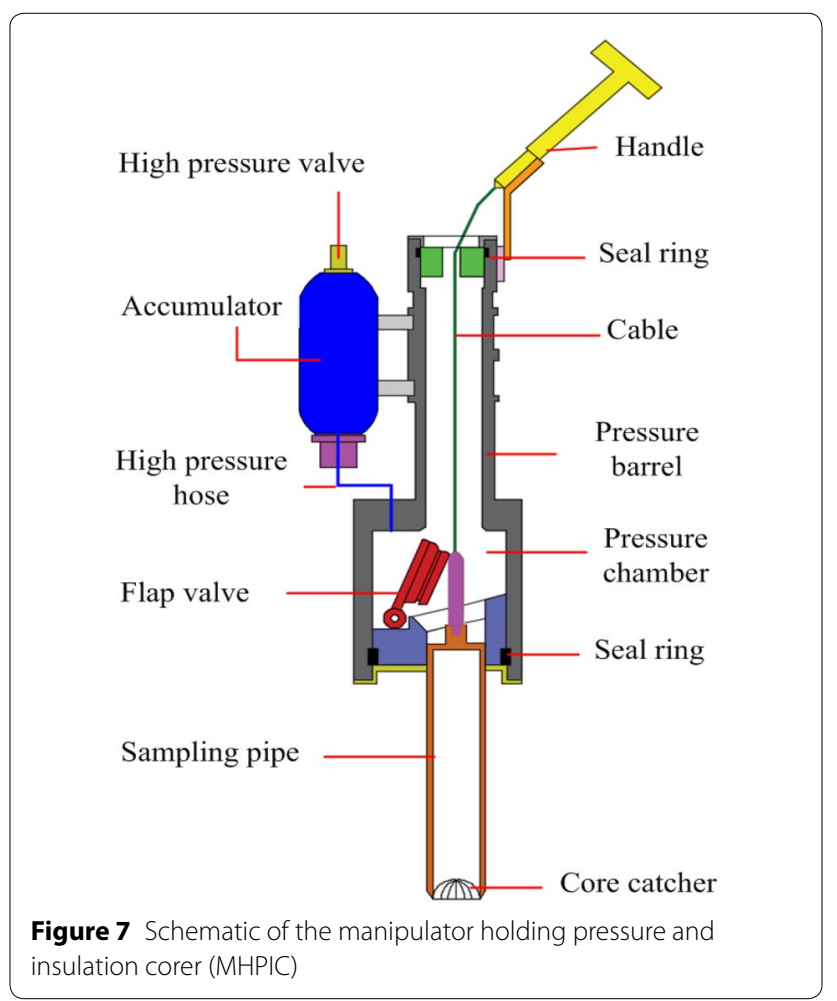




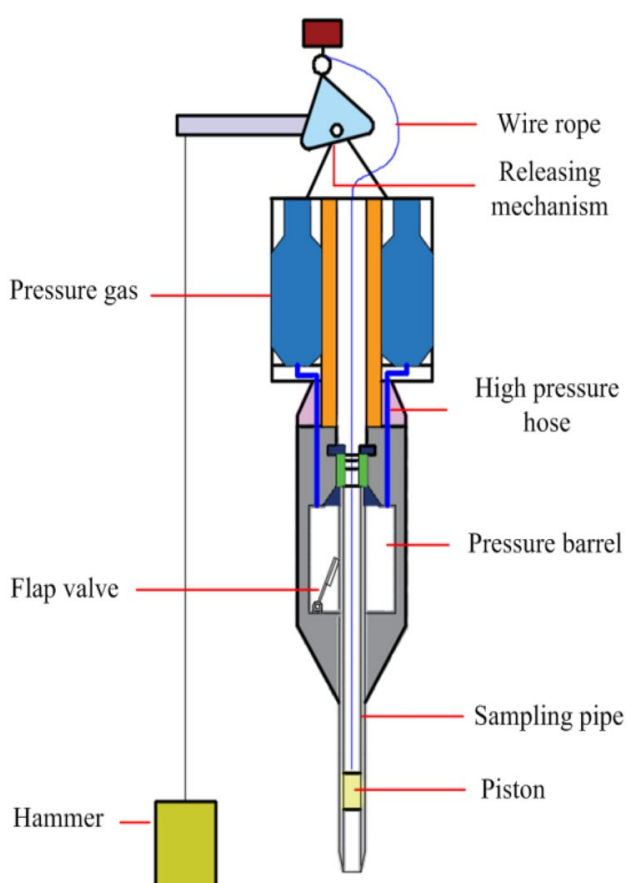

Figure 8 Schematic of the pressure and insulation corer (PIC)

connected to the sampler pressure cylinder through a high-pressure hose, and a electromagnetic valve is installed between the pressure cylinder and pneumathode. Before sampling, the pneumathode is pre-charged with sufficient gas through the high-pressure valve. After the sampling, when the pressure in the pressure cylinder drops, a sensor in the pressure cylinder sends a signal, and the electromagnetic valve starts. At this time, the pneumathode releases the gas pressure to compensate for the pressure loss in the pressure cylinder. This pressure-retaining technique is mainly used for pressure-retaining sampling in shallow sea

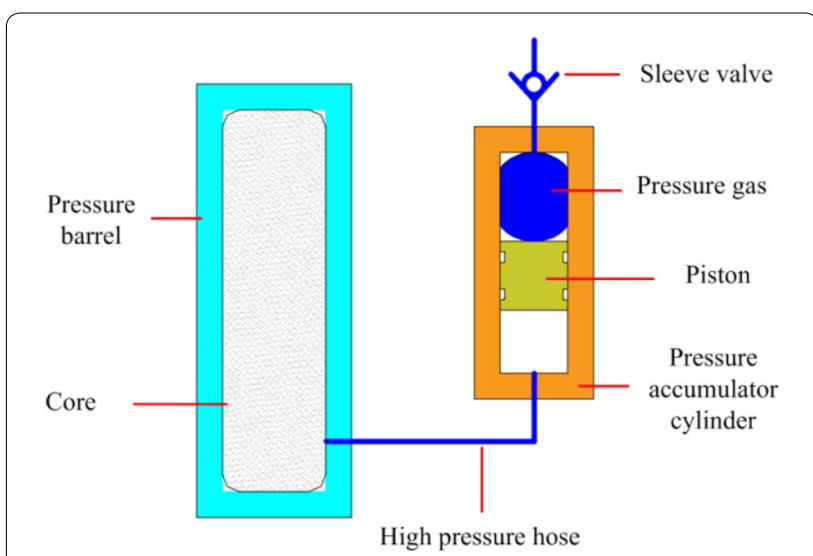

Figure 10 Schematic of passive pressure-retaining technique with external accumulator (PPRT)

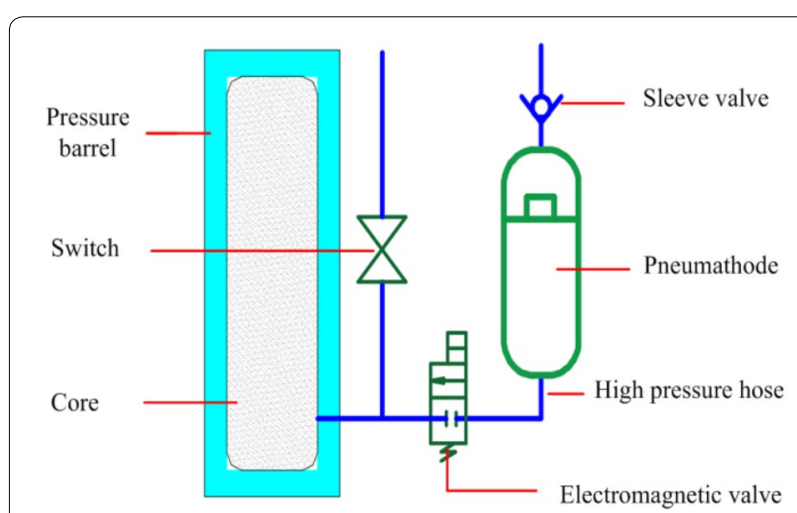

Figure 11 Schematic of active pressure-retaining technique with external accumulator (APRT)

sediment, and its pressure-retaining performance is superior. However, as the electromagnetic valve structure is used, the pressure-retaining technique is not

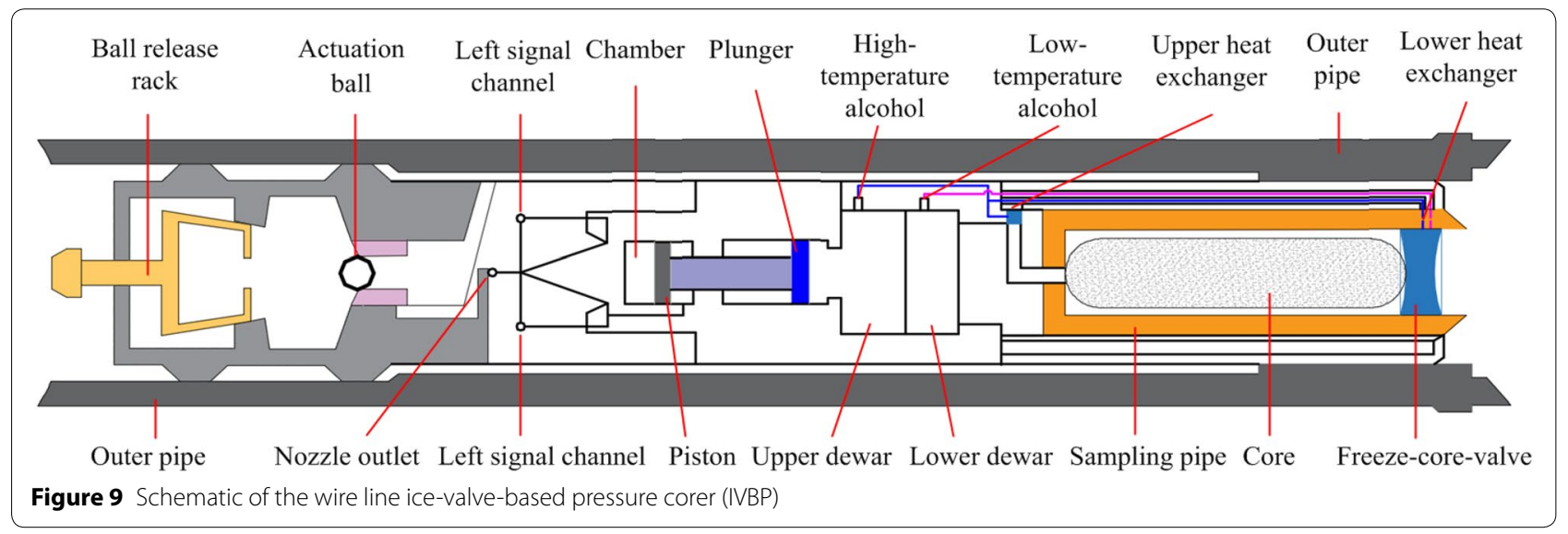


suitable in harsh environments, e.g., with ultra-high pressures and low temperatures. The gravity piston corer and PRMSC sampler use this technique.

\subsubsection{Pressure-Retaining Technique with Internal Accumulator (PRT)}

As shown in the Figure 12, the entire accumulator is placed inside the sampler. Before sampling, the accumulator chamber is filled with a certain pressure of gas through the pressure inlet and sleeve valve; the accumulator is connected to the seawater, and during the diving process of the sampler, the pressure in the accumulator gradually increases. During the sampling process, the accumulator and sampling tube are independent of each other; after the sampling, the rack and pinion mechanism work to rotate the ball valve to $90^{\circ}$, at which time the sampling cylinder is closed. The pressure entrance is connected with the accumulator, and the pressure relief hole is collected with the safety valve.

During the recovery process of the sampler, the pressure difference between the inside and outside of the sampling cylinder increases. Once the sample cylinder has a pressure loss, the high-pressure gas in the accumulator will push the piston to move left and right, so that the sampling cylinder maintains pressure stability. The PRT is compact in structure, small in size, and superior in pressure-retaining performance. It has been widely used in sampling for deep-sea sediments and in drilling for natural gas. The PCB, PCS, PTCS, FPC, HRC, Hybrid PCS, HPTC, MDP all adopt this pressureretaining technique.

\subsection{Temperature-Retaining Technique}

The temperature of seawater usually increases with depth. The temperature at depths above $6000 \mathrm{~m}$ underwater is approximately zero, a dramatic difference from the temperature of the land. Temperature is an important factor affecting the in-situ information of sediments. To obtain real information of a sediment, it is necessary to maintain the temperature of the obtained samples. At present, there are two types of temperature-retaining techniques for samplers at home and abroad:passive temperature-retaining techniques (PTRTs), and active temperature-retaining techniques (ATRTs).

\subsubsection{Passive Temperature-Retaining Techniques (PTRTs)}

A PTRT selects special temperature-retaining materials, and uses a reasonable temperature-retaining structure to maintain a constant temperature. Common passive temperature-retaining techniques include vacuum porous insulation, seawater cooling, vacuum multilayer insulation, and spraying insulation coatings on surfaces. A temperature- and pressure-retaining drill of a natural gas hydrate sampler developed by China adopts a passive temperature-retaining technique. The sampling tube adopts a double-layered pipe structure with a vacuum in the middle, an insulation coating sprayed on the inner surface of the sampling tube, and a ceramic material, such as $\mathrm{ZrO} 2 / \mathrm{CaO}$ sprayed on the external surface of the sampling tube [50,51].

The MAC and DAPC are equipped with a steel fireplace tube. Sea water acts as a cooling medium to control the temperature inside the pressure cylinder, so as to prevent the temperature of the sample from rising and causing damage to the sample. The HRC and FPC retain temperature by means of rapid freezing. The pressure and temperature-retaining gravity piston sampler developed by Marine College of Zhejiang University [52] and the HBFC designed by Beijing Institute of Exploration Engineering use a vacuum in the middle of an interlayer, an insulation coating sprayed on the inner surface of the sampling tube, and a ceramic material, such as $\mathrm{ZrO} 2 /$ $\mathrm{CaO}$, sprayed on the external surface the sampling tube. The PRMSC maintains the temperature of a sample by heating the sampling tube in a water bath.

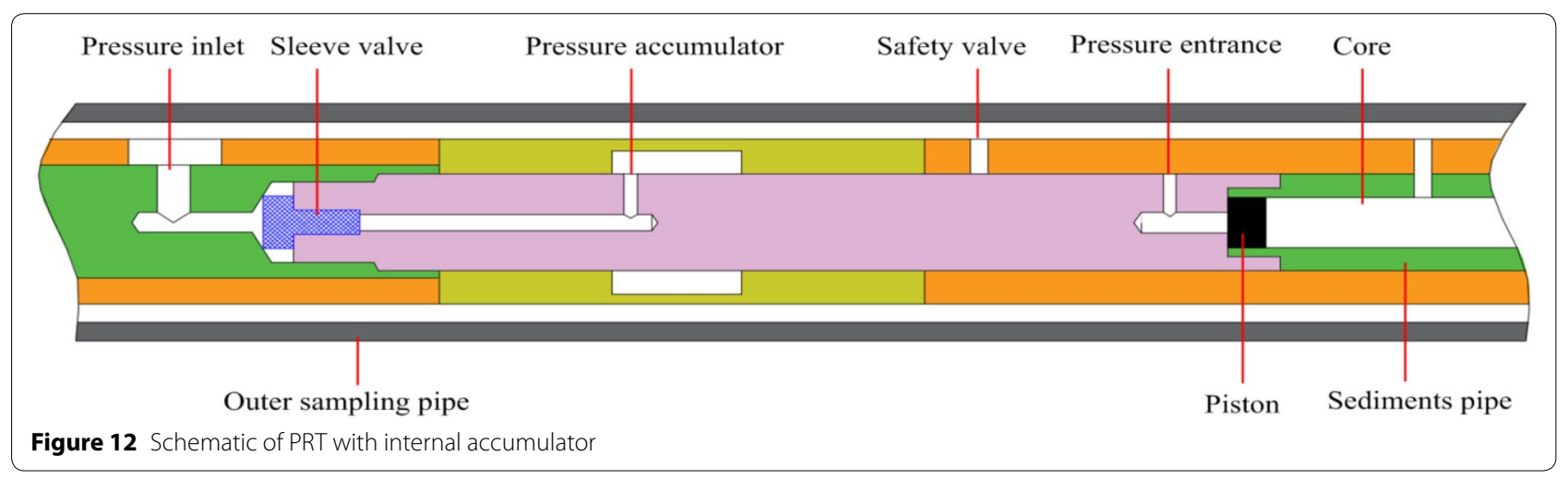


In addition, the use of an organic glass tube with a good temperature-retaining performance as a core liner can also better maintain the temperature of a core sample; an insulation material can be filled between the core liner and fidelity sampling cylinder. For example, the MAC and DAPC pressure cylinders use glass-reinforced plastic, which can not only maintain the temperature, but can also absorb radial deformations caused by pressure differences between the inside and outside of the pressure cylinder.

\subsubsection{Active Temperature-Retaining Techniques (ATRT)}

ATRTs employ temperature-retaining measures such as a thermoelectric refrigeration technique or liquid ammonia technique to maintain the temperature of the sampling tube or pressure cylinder, such that the purpose of retaining the temperature of the sample is achieved. The thermoelectric refrigeration technique, also known as semiconductor refrigeration or thermoelectric cooling, uses a theory of semiconductor refrigeration. A deep-sea refrigeration structure is generally installed inside the sampler, and the power supply is waterproofed. The entire device is a three-layer tubular structure: the innermost layer uses a copper tube as a cooling area; the middle is a thermal insulation layer filled with a heatinsulating material; and the outermost is an aluminum layer for heat dissipation [53].

Japan's PTCS achieves an active temperature-retaining function by using adiabatic and thermoelectric inner tube cooling; it is actively cooled with a slurry cooling device and low-temperature slurry during the sampling process. The temperature of the core sample can be cooled to $5{ }^{\circ} \mathrm{C}$ or lower, essentially the in-situ temperature of the deep sea at depths over $6000 \mathrm{~m}$. As a solid-state active cooling method, thermoelectric refrigeration has the advantages of no moving parts, no noise, easy integration, and the ability to directly and precisely control the temperature by adjusting the input voltage and electric current. It has attracted significant attention in the field of temperatureretaining design for marine samplers [54] (Figure 13).

A schematic of an HBFC from Jilin University is shown in Figure 14; it uses dry ice as a cooling source, and alcohol as a cooling catalyst and cooling medium $[55,56]$. When the sampler stops working, it throws a steel ball into the drill pipe, to circulate the mud again. The function of the steel ball is to block the normal circulation channel of the mud. Thus, the mud pressure increases, pushing the steel ball and valve seat down to open the
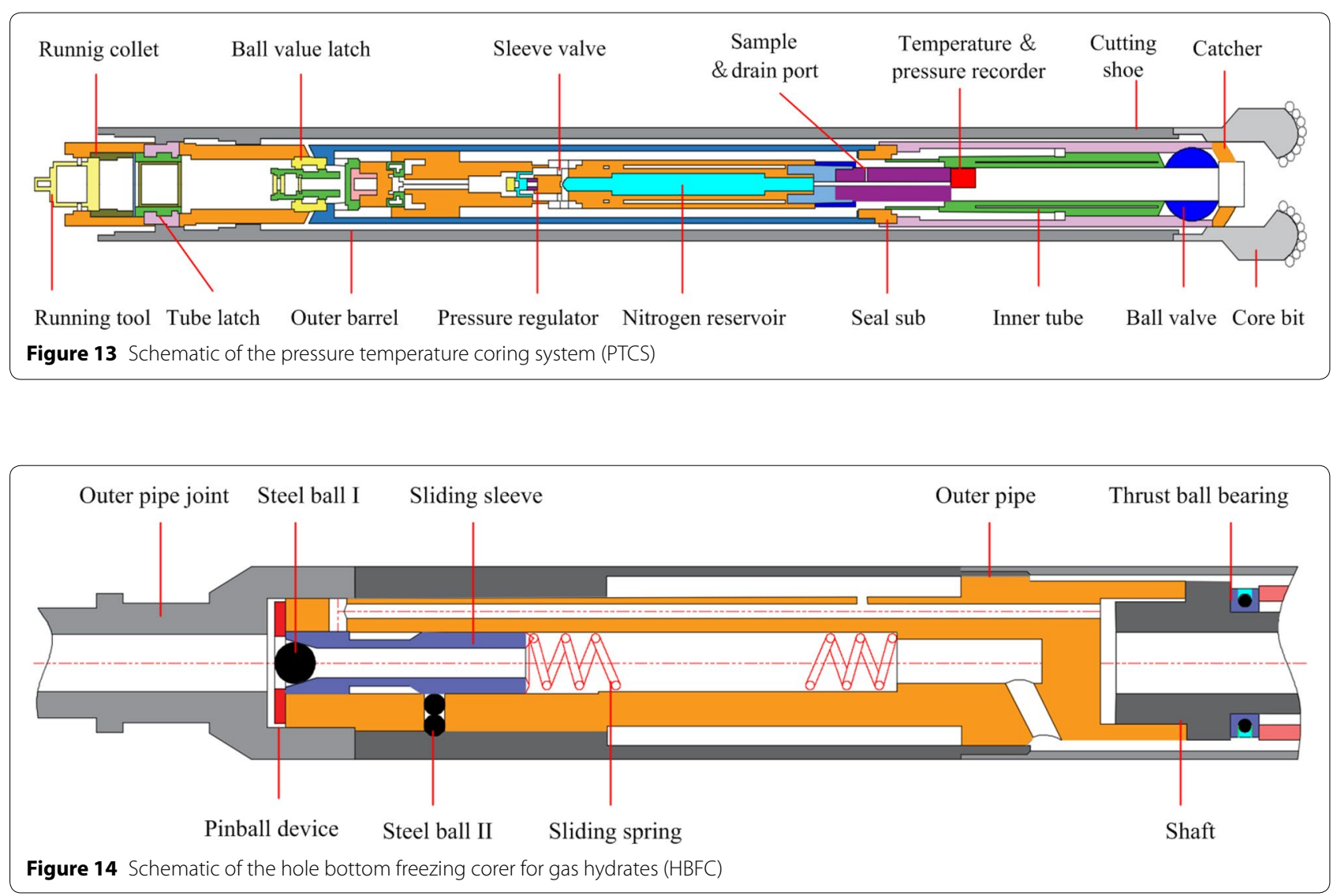
diversion port of the outer pipe joint. The mud is guided downward and pushes the control piston and alcohol upper chamber piston down. The alcohol, which passes through the dry ice chamber, is cooled into low-temperature alcohol that is pressed into the freezing chamber, freezing the drilled core. Thus, the core at the bottom of the hole is temperature-retained.

At present, temperature-retaining techniques are widely used in samplers for natural gas hydrate, but are not very common in seabed sediment samplers. The vast majority of sediment samplers do not use active temperature-retaining measures, but rather use rapid icing or liquid nitrogen freezing to maintain the temperature of sediment samples.

\subsection{Low-disturbance Sampling Technique}

When sampling in the deep sea, the interaction between the sampler and sediment often causes bending deformations and compression of the original layer of the sediment, destroying the integrity of the sample information [58]. To obtain as complete a sediment sample as possible, various types of sediment samplers employ a series of low-disturbance technical measures.

\subsubsection{Sampling Device}

The sampling device adopts a double-layered or multilayered tube structure. When a softer sediment sample is taken, the inner layer of the sampling tube is in contact with the sediment; when a harder sample sediment is taken, the outer tube with the sampling drill bit employs a certain gap in the radial direction with the sampling tube, to thereby prevent disturbance of the inner layer sample by the sampling drill bit. For example, the PCB adopts a double-layered tube structure: the inner tube is a rotating sampling tube, and the lower end of the outer tube is connected with a sampling drill bit. A gap is left between the outer tube and sampling tube, to ensure minimal disturbance to the sediment as the drill bit is drilled. The PCS, HYACE-HRC, FPC, Hybrid PCS, and "Hainiu" deep-sea sampling drill rigs all adopt this structure. For the materials of the sampling tube, organic glass tubes or materials with a small friction coefficient are recommended, so asto lower the friction with the sample and reduce disturbance to the sample. The diameter and ratio of the inside and outside diameter of the sampling tube should be optimized, and pile effects caused by geological condition sand mechanisms of bending problems of the sampling tube should be fully considered. The critical conditions should be determined, to thereby control the plastic deformation area of the samples and reduce disturbances there to.

\subsubsection{Sampling Cutter Head}

The cutter head adopts a special cutter head design such as a small inclination angle, small area ratio, small inner diameter ratio, small outer diameter ratio, and/or thin wall cylinder in front of the cutter head to reduce disturbances to the sample. Gravity-type and gravity-pistontype samplers adopt this cutter head structure.

\subsubsection{Core Catcher}

The soft core catcher is set at the lower end of the sampling cylinder. At the beginning of sampling, the petals naturally expand under the pressure of the sediment sample, and the sediment enters the sampling cylinder when the boundary disturbance is minimal. After sampling, the petals are closed under the action of gravity, to prevent the loss of sediment samples and reduce disturbances to the sediment.

\subsubsection{Piston Structure}

For a columnar sampler without a piston structure, the obtained sediment sample is often disturbed or shortened, due to the combination of the self-weight of the sediment, friction between the sampling tube and sediment, the sampling speed, and the like. Accordingly, a suction piston structure is placed inside the sampling tube to reduce or eliminate the friction between the sampling tube wall and sample, and the influence of the sample weight. The PTPC, MAC, and DAPC sample tubes all adopt this piston structure. The piston remains at the mud-water interface at the very beginning of sampling and moves up as the sampling goes on, offsetting the negative pressure due to hydrostatic pressure, and thereby obtaining the lowest-disturbance samples.

\subsubsection{Bottom Hole Assembly (BHA)}

In vibrating and rotary samplers, the sampling tube drills often use a combined structure to obtain low-disturbance sediment samples. The sampling cylinder comprises a drill core, and an inner and outer sampling cylinder. The outer cylinder is connected with the sampling drill, and the inner cylinder is a non-rotating sampling tube. The PCS, PTCS, Hybrid PCS, and APC all adopt this structure for the bottom hole assembly. For example, the extended core barrel sampler has a portion that exceeds the front end of the drill bit, and can collect soft sediment from the surface layer before the drill bit enters the sediment. The sampler can be retracted into the drill pipe when it contacts the hard sediment and continue to collect deeper sediments under the rotation of the drill bit, thereby reducing the disturbance to the sample. 


\subsection{Transfer Technique}

Submarine sediment exists in a high-pressure environment. Barophilic microorganisms cannot survive at lower pressures. At present, the pressure-retaining technique is relatively mature, and can maintain the in-situ pressure of the sediment and transfer the sediment to the sea surface without any pressure drop [59]. However, there are few studies regarding how ensure that the sediment samples transferred to the sea surface are subsequently transferred to the laboratory without pressure drops and disturbances, for further analysis. The non-pressure-drop transfer techniques mainly include the rapid cooling technique of a pressure-retaining sampler deck, rapid sample-transfer technique, sub-sample segmentation technique, multi-parameter pressure-retaining sample core scanning technique, and in-situ data recording [59-61].

In recent years, the multi-sensor core logger developed by Geotek in the UK has been able to manage sediment samples up to $2 \mathrm{~m}$ in length and $150 \mathrm{~mm}$ in diameter. The data of the sediment samples are directly analyzed by sensors, such as those for density, P-wave velocity, resistivity, magnetic susceptibility, X-ray fluorescence, linear scanning imaging, and infrared spectroscopy [62, 63] (Figure 15).

The pressure-retaining core analysis and transfer system (PCATS) developed by Geotek [64-66] can cut highpressure long-columnar sediment into sub-samples with a minimum length of $50 \mathrm{~mm}$. At present, both the HRC and FPC can be perfectly interfaced with the PCATS, to transfer samples to a laboratory's pressure chamber for fidelity analysis.

The Mini-PCATS is a small, simplified version of the PCATS [67] that is compatible with all pressure-retaining core storage chambers, in addition to other thirdparty equipment designed with standard Geotek flange clamps. A core section up to $1.2 \mathrm{~m}$ can be removed from

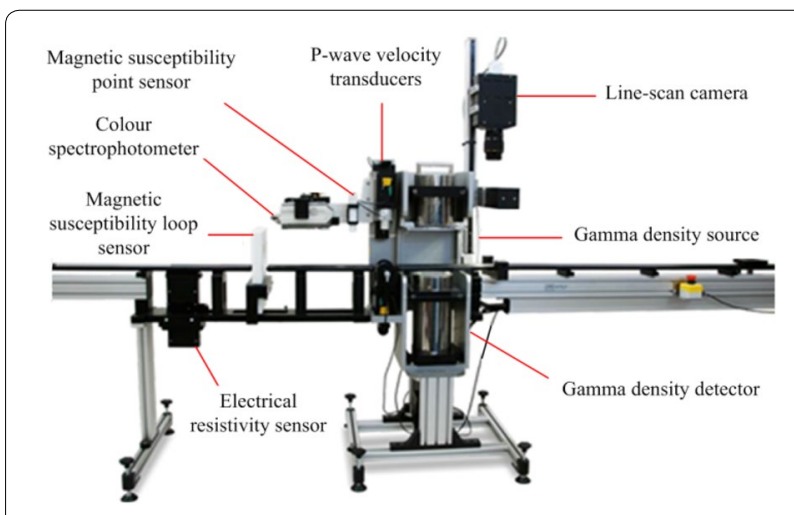

Figure 15 Multi-sensor core logger the storage chamber and accurately cut into sub-samples. These sub-samples can be transferred to a sample test unit (including a $\mathrm{K} 0$ permeameter) where the physical property parameters are measured, while maintaining pressures up to $35 \mathrm{MPa}$ (Figure 16).

Zhejiang University has developed a natural gas hydrate pressure-retaining transfer system [68] including a mechanical device for continuous sample transfer, e.g., sample grabbing, sample pushing, sample cutting, sample encapsulation, and small sample transfer. Sample cores of any length can be divided and stored under the in-situ pressure and temperature. Under $20 \mathrm{MPa}$, the internal pressure change during the sample transfer is less than $20 \%$. The system is equipped with two types of cylinders. The inner diameter of the large sample transfer cylinder is $750 \mathrm{~mm}$, and is capable of obtaining a sample with a length of $500 \mathrm{~mm}$. The inner diameter of the sample transfer cylinder is $20 \mathrm{~mm}$, and the sample length is $200 \mathrm{~mm}$. An online sonic wave detection function is available for the core. The maximum detectable diameter of the core is $67 \mathrm{~mm}$, and the sonic measurement accuracy is $0.1 \mathrm{~ms}$.

\section{Conclusions and Prospects}

A seabed sediment sampler is an indispensable sampling equipment for marine resource exploration, marine geological surveying, and marine scientific investigation. With the exploration of seabed resources expanding to deeper and wider sea areas, deep-sea sampling equipment will tend to require diversified structures, integrated functions, intelligent operation, and the ability to obtain high-fidelity samples. The key technologies of seabed sediment samplers will also be continuously

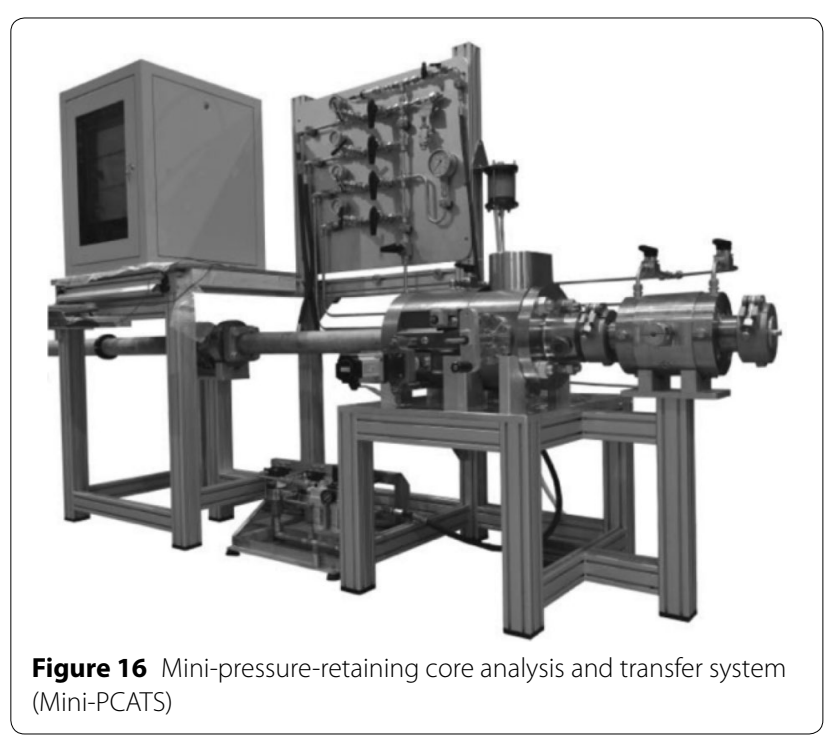


improved and perfected, so as to obtain more authentic and reliable samples to meet the ever-increasing demands on sampling. Facing a harsh environment of high pressures and low temperatures in the deep sea, many scientific challenges will be met by such deep-sea sampling equipment, such as sampling mechanisms for different sea areas, different depths, and different sediment characteristics, obtaining high-fidelity undisturbed sediment samples under high-pressure and low-temperature environments, and performing low-disturbance sediment transfers without pressure drops. Based on this, the prospects in sampling technology are discussed from the following four perspectives.

\subsection{Structural Diversity}

The deep-sea sediment samplers designed by various countries have many common points in regards to the structures for sealing, pressure and temperature-retaining, and low disturbances, and they show rich diversity, owing to different national backgrounds and design concepts. For the sealing and pressure-retaining structure, most of the current samplers use ball valves, flaps, pistons, etc. Although the above-mentioned sealing structures are reliable, there are still many challenges in the harsh environment of the deep sea. The sealing and pressure-retaining structures of the samplers will be further studied. There will be new types of structures similar to the ice seal, which can achieve efficient sealing and pressure retention for deep sea samples. In terms of the structure for temperature-retaining, new materials for deep-sea insulation will be studied and applied. In addition, precise control of the temperature of the sampler is also an important research direction for in-situ sampling in the future. In regards tol ow-disturbance structures, owing to developments in marine equipment communication technology and electronic technology, sediment samplers are undergoing structural improvements and functional expansion, such as including sonic drilling and energy impact drilling sampling in Germany, Canada, and Japan. This is also a trend of future development.

\subsection{Functional Integration}

Integration denotes the deep-sea samplers possessing not a single function, but an integration of multiple functions. For example, Germany's MAC and DAPC not only provide high-fidelity sampling, but also have a function for maintaining a low temperature, and a technique for a computerized tomography scan of the sample.

Australia's "PROD" drilling rig can not only conduct core sampling in hard rock, but can also provide pressin coring, seabed cone penetration testing (CPT) measurements, and natural gas hydrate analysis in submarine fields. Germany's new type of MDP can obtain both hard rock and sediment cores, and in-situ detection capability for some holes is also available. The US "ROVDRILL" drilling machine can perform rotating hard rock coring, press-in sediment coring, and CPT operation. The deep-sea rock corers can also be combined with the ROV (Remote Operated Vehicle), which uses ROV control to conveniently integrate various sampling devices and tools. Such deep-sea rock corers can greatly save the time and cost consumed by marine resource surveys. China's "Hainiu" sampling rig adopts a rope coring method, and is able to core soft mud and hard rock. It is equipped with a multi-functional in-situ test instrument for conducting in-situ tests on the end resistance, friction force, pore water pressure, and temperature of the stratum. It is also capable of filming the soil particles. It can be predicted that these key techniques will be fully demonstrated in future seabed sediment samplers which will no longer be merely single-functional, but rather multi-functional, i.e., performing detection, pressure and temperature retaining, and transfers with no pressure drop.

\subsection{Operational Intelligence}

Intelligentization is an important research direction for the future sampling of seabed sediment. Its main manifestation is in monitoring and control. Monitoring means the ability to monitor a deep-sea sampling process, e.g., by equipping with a GPS positioning system and camera. In the face of high pressure, low or high temperatures, low organic matter content, darkness, etc. in the deep sea environment, researchers can obtain real-time and accurate information regarding the position, power, sampling speed, and sampling resistance of samplers, and related records of the sampling conditions on the operating platform. This can provide abasis for the next operation and/ or emergency decision. Control means controlling the further actions of the sampling, including start-stop control, speed control, position control, and frequency control, based on the monitoring of relevant data.

By real-time monitoring and control of the operation of a deep-sea sediment sampler, the processes of diving, landing, sampling, and recovery can be visualized and controlled. Intelligentization can not only enhance the deep-sea sediment sampler's ability to adapt to complex and variable geological environments in the deep sea, but can also greatly improve the working efficiency of the deep-sea sediment sampler, shorten the working time, and reduce the sampling cost. Simultaneously, with the diversification of deep-sea sediment samplers, additional devices and equipment must be equipped, and those devices and equipment must work together. The entire sediment sampler must be intelligently controlled to achieve coordinated and efficient operation. 


\subsection{High Fidelity of the Sample}

Fidelity sampling means undisturbed sampling (actually low-disturbance) and temperature-and pressure-retaining sampling. With the deepening exploration of seabed resources and seabed biogeochemical cycles, whether or not high-fidelity sediment samples can be obtained for scientific research has become an important indicator for measuring the performance of deep sea sampling equipment. Different sampling equipment, owing to their different structures, functions, and principles, will inevitably cause changes in the in-situ characteristics of the sampled samples, such as changes in the temperature, pressure, stratification properties, chemical gradients, oxidation state of the variable ions, and decomposition of the organic components. Among them, changes in pressure will directly lead to the death of barophilic microorganisms. Therefore, the development of lowdisturbance, high pressure-and temperature-retaining deep-sea sediment samplers better satisfying the requirementsf or the exploration and development of deep-sea resources, deep-sea biogeochemical cycles, and marine basic science research will certainly become an important development direction of seabed resource sampling technology.

\section{Acknowledgements}

Not applicable.

\begin{abstract}
Authors' contributions
YP was in charge of the whole trial; SH wrote the manuscript; YJ and GL assisted in data collection. BW provided ideas on manuscript writing. All authors read and approved the final manuscript.
\end{abstract}

\section{Authors' Information}

Youduo Peng, born in 1964, is currently a professor and a PhD candidate supervisor at National-Local Joint Engineering Laboratory of Marine Resources Exploration Equipment and Safety Technology, Hunan University of Science and Technology, China. His main research interests include marine resources exploration and mining equipment technology, new energy technology and equipment.

Shudong He, born in1986, is currently a PhD candidate at National-Local Joint Engineering Laboratory of Marine Resources Exploration Equipment and Safety Technology, Hunan University of Science and Technology, China. He received his master's degree from Changsha University of Science and Technology, China, in 2014. His main research interests include ocean sampling equipment and reliability.

Buyan Wan, born in 1964, is currently a professor and a PhD candidate supervisor at National-Local Joint Engineering Laboratory of Marine Resources Exploration Equipment and Safety Technology, Hunan University of Science and Technology, China. His main research interests include marine resources exploration and mining equipment technology, automatic instrument research.

Yongping Jin, born in 1984, is currently a professor and a postgraduate tutor at National-Local Joint Engineering Laboratory of Marine Resources Exploration Equipment and Safety Technology, Hunan University of Science and Technology, China. His main research interests include marine resources exploration and mining equipment technology, automatic instrument research.

Guangping Liu, born in1993, is currently a PhD candidate at National-Local Joint Engineering Laboratory of Marine Resources Exploration Equipment and Safety Technology, Hunan University of Science and Technology, China. He received master's degree at Hunan University of Science and Technology, China, in 2018. His main research interests include ocean sampling equipment.

\section{Funding}

Supported by National Key Research and Development Program of China (Grant No. 2016YFC0300502), and Hunan Provincial Innovation Foundation For Postgraduate (Grant No. CX2018B658), and National Natural Science Foundation of China (Grant Nos. 51705145, 517779092). Supported by Scientific Research Fund of Hunan Provincial Education Department (Grant No. 18B205) and Hunan Province Natural Science Foundation (Grant No. 2019 JJ50182).

\section{Competing Interests}

The authors declare no competing financial interests.

Received: 23 October 2019 Revised: 7 July 2020 Accepted: 18 August 2020

Published online: 29 September 2020

\section{References}

[1] R Sharma. Deep-sea mining: Economic, technical, technological, and environmental considerations for sustainable development. Marine Technology Society Journal, 2011, 45(5): 28-41.

[2] E Ramirez-Llodra, A Brandt, R Danovaro, et al. Deep, diverse and definitely different: unique attributes of the world's largest ecosystem. Biogeosciences, 2010, 7: 2851-2899.

[3] L M Peoples, M Norenberg, David Price, et al. A full-ocean-depth rated modular lander and pressure-retaining sampler capable of collecting hadal-endemic microbes under in situ conditions. Deep Sea Res., 2019, Part I(143): 50-57.

[4] S J Kim, C Kato. Sampling, isolation, cultivation, and characterization of piezophilic microbes. In: Handbook of hydrocarbon and lipid microbiology, 2010: 3869-3881.

[5] S J Wu, CJ Yang, Y Chen. A study of the sealing performance of a new high-pressure cone valve for deep-sea gas-tight water samplers. Journal of Pressure Vessel Technology, 2010, 132(4): 0094-9930.

[6] J A Mikucki, P A Lee, D Ghosh, et al. Subglacial Lake Whillans microbial biogeochemistry: a synthesis of current knowledge. Philosophical Transactions of the Royal Society A: Mathematical, Physical and Engineering Sciences, 2015, 374(2059): 20140290.

[7] Shaojun Liu, Chang Liu, Yu Dai. Status and progress on researches and developments of deep ocean mining equipments. Journal of Mechanical Engineering, 2014, 50(2): 8-18. (in Chinese)

[8] M Magagnoli. A new coring method in deep water. Marine Georesources \& Geotechnology, 2016, 35(4): 496-503.

[9] A Cario, G C Oliver, K L Rogers. Exploring the deep marine biosphere: Challenges, innovations, and opportunities. Frontiers in Earth Science, 2019, 7: 225.

[10] M Garel, P Bonin, S Martini, et al. Pressure-retaining sampler and highpressure systems to study deep-sea microbes under in situ conditions. Frontiers in Microbiology, 2019, 10: 453.

[11] MNA. Peterson design and operation of a wire-line pressure core barrel. DeepSea Drilling Project Technical Report PB-85-112282/XAB TR-16. La Jolla, CA(USA): Scripps Institution of Oceanography. 1984.

[12] T J G Francis, Y D E Lee. Determination of in situ sediment shear strength from advanced piston corer pullout forces. Marine Georesources and Geotechnology, 2000, 18(4): 295-314.

[13] T L Pettigrew. Design and preparation of a wire-line pressure core sampler(PCS). ODP Technical Note No. 17, 1992.

[14] H Amann, H-J Hohnberg, R Reinelt. HYACE-a novel autoclave coring equipment for systematic offshore gas hydrate sampling. Deutsche Wissenschaftliche Gesellschaft für Erdgas und Kohle e.V. (DGMK), 1997, 9706: 37-49.

[15] P J Schultheiss, M Holland, G Humphrey. Wireline coring and analysis under pressure: Recent use and future developments of the HYACINTH system. Scientific Drilling, 2009(7): 44-50.

[16] M Kawasaki, S Umezu, M Yasuda. Pressure temperature core sampler (PTCS). Journal of the Japanese Association for Petroleum Technology, 2006, 71(1): 139-147. 
[17] Y Kubo, Y Mizuguchi, F Inagaki, et al. A new hybrid pressure-coring system for the drilling vessel Chikyu. Scientific Drilling, 2014, 17: 37-43.

[18] F Abegg, H-J Hohnberg, T Pape, et al. Development and application of pressure-core-sampling systems for the investigation of gas-hydratebearing sediments. Deep Sea Research Part I, 2008, 55(11): 1590-1599.

[19] P J Schultheiss, J T Aumann, G D Humphery. Pressure coring and pressure core analysis for the upcoming Gulf of Mexico Joint Industry Project coring operation. Offshore Technology Conference, 2010, OTC20827, Houston, USA. http://dx.doi.org/10.4043/20827-MS.

[20] T Freudenthal, G Wefer. Scientific drilling with the sea floor drill rig MeBo. Scientific Drilling, 2007, 5: 63-66.

[21] A Khizar, S Giovanni, T Catalin. Review of pressure coring systems for offshore gas hydrates research. Underwater Technology, 2015, 33(1): 19-30.

[22] Y B Gao, H Q Li, Y P Chai, et al. Development status and trend of deep-sea high technology. Ocean Engineering, 2010(3): 119-124. (in Chinese)

[23] G J Ni. The development trend of Marine resources exploitation technology and the development emphases of our country. Marine Technology, 2009, 28(1): 133-136. (in Chinese)

[24] HY Zhu, Q Y Liu, G R Wang, et al. Research status and progress of gas hydrate sampler. Natural Gas Industry, 2009, 29(6): 63-67. (in Chinese)

[25] Y Liu, D Wu, D Li, et al. Applications and research progress of hydraulic technology in deep sea. Journal of Mechanical Engineering, 2018, 54(20): 14-23. (in Chinese)

[26] W C Cui, Y Hu, W Guo. Chinese journey to the challenger deep: The development and first phase of sea trial of an 11,000-m Rainbowfish ARV. Marine Technology Society Journal, 2017, 51(3): 23-35. (in Chinese)

[27] D L Dong, X B Xiang, J R Zheng, et al. Design and implementation of monitoring system for deep sea ore sampling machine. Intelligent Robotics and Applications, 2019, 11742: 276-288.

[28] D Q Lu, Z J Ding, D W Li, et al. Studies and applications of cobalt-rich crust core samplers mounted on "Jiao Long" manned submersibles. China Mechanical Engineering, 2019, 30(5): 603-607. (in Chinese)

[29] L Yang, Z J Ding, D W Li, et al. Deep-sea portable core sampling apparatusin situ based on the "Jiao Long" manned submersible. Journal of Ocean Technology, 2014(1): 115-119.

[30] Y P Jin, B Y Wan, D S Liu, et al. Dynamic analysis of launch \& recovery system of seafloor drill under irregular waves. Ocean Engineering, 2016, 117: 321-331.

[31] D S Liu, Y P Jin, B Y Wan, et al. Review and development trends of deepsea mineral resource core sampling technology and equipment. China Mechanical Engineering, 2014, 23: 3255-3265.

[32] B Y Wan, X J Huang. Development of deep-sea shallow stratum core sampling drill. Mining Research and Development, 2006: 49-51.

[33] BY Wan, G Zhang, X J Huang. Cobalt-rich crust core sampler mounted on human-operated vehicle. Nonferrous Metals, 2009, 61(4): 138-144.

[34] B Y Wan, G Zhang, X J Huang. Development of 20-meter core sampling drill for sediment. Marine Engineering Equipment and Technology, 2015, 2(1): 1-5.

[35] B Y Wan, G Zhang, X J Huang. Research on deep sea pressure-tight rock core sampling technology. Mining Research and Development, 2009, 29(6): 47-53.

[36] H W Qin, LY Gu, S L Li, et al. Pressure tight piston corer-a new approach on gas hydrate investigation. China Ocean Engineering, 2005, 19(1): 121-128.

[37] HY Zhu, Q Y Liu, G R Wang, et al. A pressure and temperature preservation system for gas-hydrate-bearing sediments sampler. Petroleum Science and Technology, 2013, 31(6): 652-662.

[38] J W Chen, Y H Chen. A novel active seafloor pressure-retained multitube sediment corer. Marine Technology Society Journal, 2014, 48(3): 43-56.

[39] J P Chai, Y Zhao, H L Ruan, et al. Development of Marine insulation and pressure-retaining sampling drill. Exploration Engineering, 2016, 43(2): 60-63. (in Chinese)

[40] B Yang, R F Salant. Elastohydro dynamic lubrication simulation of O-ring and U-cup hydraulic seals. ARCHIVE Proceedings of the Institution of Mechanical Engineers Part J Journal of Engineering Tribology, 2011, 225(7): 603-610.
[41] T Sukumar, M Subramanian. Design and optimization of lip seal for air braking system. SAE Technical Paper, 2015-26-0215, 2015.

[42] I Gallmetzer, A Haselmair. An innovative piston corer for large-volume sediment samples. Limnology and Oceanography: Methods, 2016, 14(11): 698-717.

[43] Y J Luo, J M Peng, M Sun, et al. An ice-valve-based pressure-coring system for sampling natural hydrate-bearing sediments: Proof-of-concept laboratory studies. Journal of Natural Gas Science and Engineering, 2015, 27: 1462-1469.

[44] Y D Park, G S Son. Integrity evaluation of ice plugged pipes applied on short jacket. Journal of the Korean Nuclear Society, 2002, 34(2): 105-116.

[45] M Akyurta, A N A Aljawi, S Aldousari. Ice-based technique for burst testing of tubular elements. Japanese Psychological Review, 2005, 16(1): 103-130.

[46] Y Dück, L Liu, A Lorke, et al. A novel freeze corer for characterization of methane bubbles and assessment of coring disturbances. Limnology and Oceanography: Methods, 2019, 17(5):305-319.

[47] N Inada, K Yamamoto. Data report: Hybrid Pressure Coring System tool review and summary of recovery result from gas-hydrate related coring in the Nankai Project. Marine and Petroleum Geology, 2015, 66: 323-345.

[48] D Y Wu, J M Peng, M Z Sun, et al. Experimental study on a pressure-coring technology based on a freeze-core valve for marine hydrate-bearing sediment sampling. Journal of Natural Gas Science and Engineering, 2016, 33: 135-142.

[49] Y Dück, A Lorke, C Jokiel, et al. Laboratory and field investigations on freeze and gravity core sampling and assessment of coring disturbances with implications on gas bubble characterization. Limnology and Oceanography, 2019, 17(11): 585-606.

[50] G Dell'Agli, G Mascolo. Low temperature hydrothermal synthesis of ZrO2CaO solid solutions. Journal of Materials Science, 2000, 35(3): 661-665.

[51] D G Giovanni, C Blasi, M Schioppa, et al. Structure and thermal properties of heat treated plasma sprayed ceria-yttria co-stabilized zirconia coatings. Ceramics International, 2010, 36(3): 961-968.

[52] S L Li, Y Chen, HW Qin, et al. Development of pressure piston corer for exploring natural gas hydrates. Journal of Zhejiang University, 2006, 40(5): 888-892.

[53] Y Q Zhang, J H Sun, H T Zhao, et al. Test research on in-situ sampler for gas hydrate. Exploration Engineering: Rock \&Soil Drilling and Tunneling, 2007, 7: 62-65.

[54] L Dong, GT Zhao. A review of thermoelectric cooling: Materials, modeling and applications. Applied Thermal Engineering, 2014, 66(1-2): 15-24.

[55] G H Chen, W Guo, R Jia, et al. Design and experimental research on cold storage chamber of the freezing sampler for gas hydrates at hole bottom. Exploration Engineering, 2016, 43(10): 182-187. (in Chinese)

[56] Y Q Zhang, J H Sun, H T Zhao. Test research on in-situ sampler for gas hydrate. Exploration Engineering, 2007, 34(9): 62-65. (in Chinese)

[57] L C Skinner, I N McCave. Analysis and modeling of gravity and piston coring based on soil mechanics. Marine Geology, 2003, 199(1): 181-204.

[58] N Inada, K Yamamoto. Data report: Hybrid Pressure Coring System tool review and summary of recovery result from gas-hydrate related coring in the Nankai Project. Marine and Petroleum Geology, 2015, Part II (66): 323-345.

[59] TYun, G Narsilio, J Santamarina, et al. Instrumented pressure testing chamber for characterizing sediment cores recovered at in-situ hydrostatic pressure. Marine Geology, 2006, 229: 285-293.

[60] K Yamamoto. Overview and introduction: pressure core-sampling and analyses in the 2012-2013 MH21 offshore test of gas production from methane hydrates in the eastern Nankai Trough. Marine and Petroleum Geology, 2015, 66: 296-309.

[61] J Santamarina, S Dai, J Jang, et al. Pressure core characterization tools for hydrate-bearing sediments. Scientific drilling, 2012, 14: 44-48.

[62] J A Priest, M Druce, J Roberts, et al. PCATS Triaxial: A new geotechnica apparatus for characterizing pressure cores from the Nankai Trough, Japan, 2015, 66(2): 460-470. 
[63] A Liernur, A Schomburg, P Turberg, et al. Coupling X-ray computed tomography and freeze-coring for the analysis of fine grained lowcohesive soils. Geoderma, 2017, 308: 171-186.

[64] J A Priest, J A Hayley, W E Schultheiss, et al. PCATS triaxial testing: Geomechanical properties of sediments from pressure cores recovered from the Bay of Bengal during expedition NGHP-02. Marine and Petroleum Geology, 2018, 108: 424-438.

[65] J Priest, M Druce, J Roberts, et al. PCATS Triaxial: A new geotechnical apparatus for characterizing pressure cores from the Nankai Trough, Japan. Marine and Petroleum Geology, 2015, 91: 664-664.

[66] P Schultheiss, M Holland, J Roberts, et al. Advances in wireline pressure coring, core handling, and core analysis related to gas hydrate drilling investigations. Proceedings of the 9th International Conference on Gas Hydrates (ICGH 2017), Denver, USA, June 25-30, 2017.

[67] J B Liu, JW Chen, F Liu, et al. Development of one pressure core transfer device for one long gravity-piston pressure-retained corer. Oceans Conference, St Johns, Canada, 2014.

[68] P H Zhang, JW Chen, Q L Gao, et al. Research on a temperature control device for seawater hydraulic systems based on a natural gas hydrate core sample pressure-retaining and transfer device. Energies, 2019, 12(20): 3990

\section{Submit your manuscript to a SpringerOpen ${ }^{\odot}$ journal and benefit from:}

- Convenient online submission

- Rigorous peer review

- Open access: articles freely available online

- High visibility within the field

- Retaining the copyright to your article

Submit your next manuscript at $\gg$ springeropen.com 